\title{
Modulation of Gut-Brain Axis Improves Microbiome, Metabolism, and Mood
}

\author{
Shawn M. Talbott ${ }^{1}$, Julie A. Talbott ${ }^{2}$, Bret J. Stephens ${ }^{3}$, and Marc P. Oddou ${ }^{3}$ \\ ${ }^{1}$ Amare Global, Irvine, CA, USA, ${ }^{2}$ EQQIL, Draper, UT, USA ${ }^{3}$ Wasatch Scientific, Murray, UT, \\ USA
}

Corresponding Author: Shawn Talbott, EQQIL, 648 E Rocky Knoll Draper, UT 84020

Submission Date: December 18, 2019 Acceptance Date: January 28 ${ }^{\text {th }}$, 2020 Publication Date: January $31^{\text {st }}, 2020$

Citation: Talbott S.M., Talbott J.A, Stephens B.J., and Oddou M.P. Modulation of Gut-Brain Axis Improves Microbiome, Metabolism, and Mood. Functional Foods in Health and Disease 2020; 10(1): 37-54. DOI: https:/doi.org/10.31989/ffhd.v10i1.685

\begin{abstract}
Objective: There is a close bidirectional relationship between overweight/obesity and depression, which may be largely modified through the microbiome and the gut-brain axis. Previous research has shown targeted weight loss effects and anti-depressive benefits of diets high in fiber and phytonutrients and low in sugar and processed foods. Thus, our objective was to determine changes in parameters common to both obesity and depression (e.g., microbiome balance, metabolic biomarkers, and psychological mood state) following a coordinated supplementation regimen combining probiotics, prebiotics, and phytonutrients ("phytobiotics").
\end{abstract}

Methods: Thirty-three (33) healthy subjects participated in a 6-week supplementation trial (Amare "Project b3") containing a targeted blend of probiotics, prebiotics, and phytobiotics. Microbiome balance was assessed in fecal samples using a novel PCR-based analysis (BiomeTracker) that has previously compared favorably to $16 \mathrm{~S}$ sequencing. Biomarkers, including blood lipids, glucose, cortisol, and butyrate kinase, were assessed as indicators of effects on cardiovascular, inflammatory, and energy metabolism. Psychological mood state was assessed using the validated Profile of Mood States survey (POMS) to generate scores for Global Mood State and six sub-scales (Depression, Tension, Fatigue, Anger, Confusion, and Vigor).

Results: Following supplementation, there was a significant increase in populations of "good" bacteria (+8\% Bifidobacterium, $+33 \%$ Lactobacillus, $+62 \%$ S. Thermophilus, $+90 \%$ Akkermansia) as well as bacterial ratios associated with a healthier "obesity-resistant" metabolism (+6\% composite score, $-11 \%$ Firmicutes, $+6 \%$ Bacteroidetes, $-14 \%$ F/B ratio). Metabolites associated with stress and glycemic control improved post-supplementation ( $-11 \%$ cortisol; $+89 \%$ butyrate kinase, $-6 \%$ glucose), as did body fat (-2\%) and blood lipids (-8\% total cholesterol, $-5 \%$ LDL, $+3 \%$ HDL, $-23 \%$ triglycerides, $-7 \%$ TC/HDL). Psychological indices were significantly improved post- 
supplementation for both positive (+17\% Global Mood; $+23 \%$ Vigor) and negative mood states ($38 \%$ Depression; $-41 \%$ Tension; - $42 \%$ Fatigue; $-31 \%$ Confusion; - $39 \%$ Anger).

Conclusions: These results demonstrate the close relationship between microbiome balance, systemic metabolism, and psychological parameters - and the utility of targeted supplementation to optimize gut-brain-axis balance for both improved metabolism and enhanced mental wellness.

Keywords: Obesity; Depression; Anxiety; Stress; Probiotics; Prebiotics; Diet; Supplement

\section{INTRODUCTION}

Globally, more than 1.9 billion people struggle with overweight, while depression affects over 350 million people [1]. More than a decade has passed since the initial discovery of the close link between the gut microbiota and obesity $[2,3]$. One of the predominant mechanisms underlying the microbiome/obesity relationship is the metabolic endotoxemia hypothesis, whereby an impaired or permeable gut barrier allows translocation of endotoxins from the gut lumen into systemic circulation, thereby leading to low-grade inflammation and metabolic disorders including obesity and diabetes.The gut microbiome is also closely linked to psychological mood states, including depression and anxiety, through multiple communication pathways, including neurotransmitters, the immune system, and the inflammatory cascade via the gut-brain axis [4]. Indeed, a close bi-directional relationship between overweight and depression has repeatedly been established, whereby being overweight increases the risk of developing depression, and having depression increases the risk of becoming overweight $[5,6]$. In addition, antidepressant medications often lead to weight gain [7], and dietary restriction for weight loss often exacerbates depression [8].

Probiotics are live micro-organisms that confer health benefits to the host [9], whereas prebiotics are fibers that selectively improve the growth of beneficial gut microbes [10]. An emerging class of functional foods, termed "psychobiotics," encompasses probiotics (bacteria), prebiotics (fibers), and phytobiotics (phytonutrients) that additionally confer psychological benefits related to mood and cognition [11]. A number of recent clinical trials have shown promising weight management benefits of probiotics [12-15] and prebiotics [16, 17], as well as reductions in anxiety and depression with specific probiotic strains [18] and prebiotic fibers [19].

Because many prior studies in this area have examined "diseased" subjects (e.g., those with diagnosed "gut problems" such as irritable bowel syndrome, "metabolic problems" such as obesity or diabetes, or "psychological problems" such as major depressive disorder or generalized anxiety disorder), this study aimed to determine the holistic benefits of a multi-ingredient functional food on microbiome balance, metabolic markers, and mood state in a population of normal weight, "healthy-stressed" adults.

\section{METHODS}

\section{Study design}

This study was done in accordance with the Helsinki Declaration, as revised in 1983, for clinical research involving humans, and all procedures, measurements, and informed consent processes were reviewed and approved by an external third-party review board (Aspire IRB; Santee, CA). 
Thirty-three (33) volunteers, free of prescription medications for depression, anxiety, diabetes, or obesity, signed informed consent documents after the study details were explained. Subjects selfadministered the supplements daily (Project b3; Amare Global, Irvine, CA) for 6-weeks and were contacted weekly to remind them to take their supplement daily (Table 1). The 6-week duration was selected as more representative of persistent changes in mood state that may result from microbiome modulation and superior neurotransmitter balance, as opposed to short-term changes in emotions that may be more closely linked with stressors of daily living. Unfortunately, 6-weeks is often not a sufficient duration of time to observe significant changes in body weight, but since our main objective was not overt weight loss, but rather to assess obesity-related metabolic traits (e.g., microbiome, cholesterol, cortisol, etc.), the 6-week duration was judged to be sufficient to evaluate changes in these aspects of metabolism.

Table 1. Key Bioactive Ingredients in Supplement (Project b3, Amare Global)

\begin{tabular}{|c|c|c|}
\hline Ingredient & Purpose/Effect & Supplier \\
\hline Lactobacillus helveticus R0052 [20-22] & Serotonin/Depression & $\begin{array}{l}\text { Lallemand Health Solutions, Mon- } \\
\text { treal, Canada }\end{array}$ \\
\hline Bifidobacterium longum R0175 [22-24] & GABA/Anxiety & $\begin{array}{l}\text { Lallemand Health Solutions, Mon- } \\
\text { treal, Canada }\end{array}$ \\
\hline Lactobacillus rhamnosus R0011 [20, 25-26] & Cortisol/Stress & $\begin{array}{l}\text { Lallemand Health Solutions, Mon- } \\
\text { treal, Canada }\end{array}$ \\
\hline Bimuno GOS [27-29] & Microbiome/Resilience & Clasado BioSciences, UK \\
\hline Sunfiber Guar Gum Galactomannan [30-32] & Microbiome/Resilience & Taiyo, Minneapolis, MN, USA \\
\hline Suntheanine L-theanine [33-35] & Stress/Tension & Taiyo, Minneapolis, MN, USA \\
\hline $\begin{array}{l}\text { Applephenon Asian Apple Polyphenols [36- } \\
38 \text { ] }\end{array}$ & Gut-Brain Axis Signaling & BGG, Beijing, China \\
\hline $\begin{array}{l}\text { Enovita French Grape Seed Polyphenols } \\
\text { [39-41] }\end{array}$ & Gut-Brain Axis Signaling & Indena, Milan, Italy \\
\hline $\begin{array}{l}\text { Enzogenol New Zealand Pine Bark Poly- } \\
\text { phenols [42-44] }\end{array}$ & Gut-Brain Axis Signaling & Enzo, Auckland, New Zealand \\
\hline Pomma+ Pomegranate Extract [45-47] & Brain Activation & Stauber, Fullerton, CA, USA \\
\hline $\begin{array}{l}\text { ProDigest Artichoke Leaf Extract plus Gin- } \\
\text { ger Root Extract [48-50] }\end{array}$ & Gut Motility & Indena, Milan, Italy \\
\hline
\end{tabular}




\begin{tabular}{|c|c|c|}
\hline $\begin{array}{l}\text { Wellmune Baker's Yeast Beta 1,3/1,6 Glu- } \\
\text { can }[51-53]\end{array}$ & Immune Priming & Kerry Group, Tralee, Ireland \\
\hline $\begin{array}{l}\text { MycoFusions high-polyphenol purple } \\
\text { mushrooms (Maitake, Shiitake, Agaricus, } \\
\text { Chaga) [54-56] }\end{array}$ & Immune Priming & NutraGenesis, Brattleboro, VT, USA \\
\hline FucoMax Fucoidan [57-59] & Gut integrity & BGG, Beijing, China \\
\hline $\begin{array}{l}\text { Calcium/Magnesium Butyrate (short-chain } \\
\text { fatty acid) [60-62] }\end{array}$ & Gut integrity & Phoenix Formulations, Tempe, AZ \\
\hline Zinc Carnosine Complex [63-65] & Gut integrity & Phoenix Formulations, Tempe, AZ \\
\hline Artesa Chickpea Protein [66-68] & Gut Integrity & PLT Health, Morristown, NJ \\
\hline ETAS Japanese Asparagus Extract [69-71] & Stress / Heat Shock Proteins & AminoUp, Sapporo, Japan \\
\hline AHCC Shiitake Mycelia Extract [72-74] & $\begin{array}{l}\text { Anxiety / microRNA Signal- } \\
\text { ing }\end{array}$ & AminoUp, Sapporo, Japan \\
\hline
\end{tabular}

\section{Dietary supplement}

All subjects consumed one serving daily of a natural multi-ingredient targeted mental wellness supplement regimen (Project b3, Amare Global, Irvine, CA, USA) containing probiotic bacteria, prebiotic fibers, and phytobiotic plant extracts and phytonutrients (Table 1). In recognition of the recently demonstrated strain-specific benefits of probiotics and structure-specific benefits of prebiotics, the Supplement contained research-validated bacterial strains (e.g., Lactobacillus helveticus R0052 for serotonin/depression; Bifidobacterium longum R0175 for GABA/anxiety; and Lactobacillus rhamnosus R0011 for cortisol/stress); clinically-proven prebiotic fibers (galactooligosaccharides, GOS, Bimuno, Clasado BioSciences, UK; and galactomannan, partially hydrolyzed guar gum, PHGG, Sunfiber, Taiyo International, Minneapolis, MN USA); and selected nutrients with demonstrated mental wellness functional benefits across the gut-brain-axis, including L-theanine (Suntheanine, Taiyo International); Asian Apple Polyphenols (Applephenon, BGG, Beijing, China); French Grape Seed Polyphenols (Enovita, Indena, Milan, Italy); New Zealand Pine Bark Polyphenols (Enzogenol, Enzo, Auckland, New Zealand); Artichoke Leaf Extract plus Ginger Root Extract (ProDigest, Indena, Milan, Italy); Chickpea protein (Artesa, PLT Health, Morristown, NJ); Japanese Asparagus extract (ETAS, AminoUp, Sapporo, Japan); and Shiitake mushroom mycelia (AHCC, AminoUp, Sapporo, Japan).

\section{Microbiome Assessment}

Microbiome analysis of fecal samples was carried out using the complete BiomeTracker system (Wasatch Scientific, Murray, UT). Briefly, fecal samples were obtained by nylon swab and placed 
into a preservative binding buffer to lock the composition of bacteria in place. DNA was then purified by following the recommended procedure and using the provided DNA columns. Reaction mixtures were set up as recommended with the components provided (WS\#1- WS\#8), and 20ng of DNA from each sample was added to the reaction mixtures. Samples were processed using the recommended conditions on an ABI 7500 Fast (Applied Biosystems) instrument in duplicate. Threshold values were input into the normalization/quantification template provided.

\section{Metabolic Assessments}

Lipid Profile (including total cholesterol/TC, low-density lipoproteins/LDL, high-density lipoproteins/HDL, TC/HDL ratio) and blood glucose were assessed by fingerstick with all subjects in an overnight fasted condition (Cholestech LDX Analyzer, Abbott/Alere, Charlottesville, VA). Cortisol was measured as free cortisol in first-morning saliva samples (Salimetrics, Carlsbad, CA). Body fat percentage was assessed by bioelectrical impedance analysis (BIA) in a fasted condition before and after 6-weeks of supplementation (InBody, Seoul, South Korea).

\section{Psychological Mood Assessment}

We employed the Profile of Mood States (POMS) questionnaire to measure six primary psychological factors (tension, depression, anger, fatigue, vigor, or confusion) plus the combined global mood state as an indication of subjective well-being. The POMS methodology has been used in $\sim 3,000$ studies, and its validity is well established [75]. The POMS profile uses 65 adjective-based intensity scales scored on a 0-4 hedonic scale (e.g., "not at all" to "extremely"). The 65 adjective responses are categorized into the six mood factors (tension, depression, anger, fatigue, vigor, or confusion), tabulated, scored, and analyzed. The output of the POMS questionnaire is an assessment of the positive and negative moods of each subject at baseline and post-supplementation (6 weeks).

\section{Data Management and Analysis}

All questionnaires were collected and stored in a central location and transcribed to a central database. Data were identified by subject number and examined for accuracy and completeness. Tabulated data were analyzed with JMP 14.0 (SAS Institute, Cary, NC) using standard parametric paired t-tests, and significance was assessed with a 2-tailed alpha level set at 0.05 .

\section{RESULTS}

\section{Body Composition}

As expected, following the short 6-weeks of dietary supplementation, with no major alterations in dietary intake or physical activity patterns, there was no significant change in average body weight ( $176 \mathrm{lbs})$ or muscle mass ( $71 \mathrm{lbs})$, but there was a surprising and meaningful drop of $2 \%$ in total body fat levels from $27 \%$ to $25 \%$ ( $\mathrm{p}<0.05$; Figure 1). 

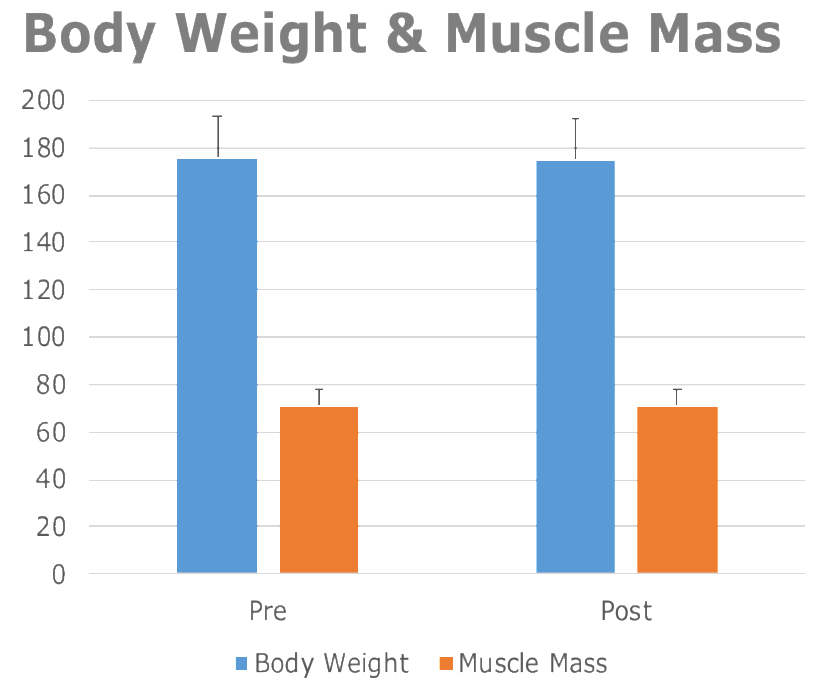

Body Fat \%

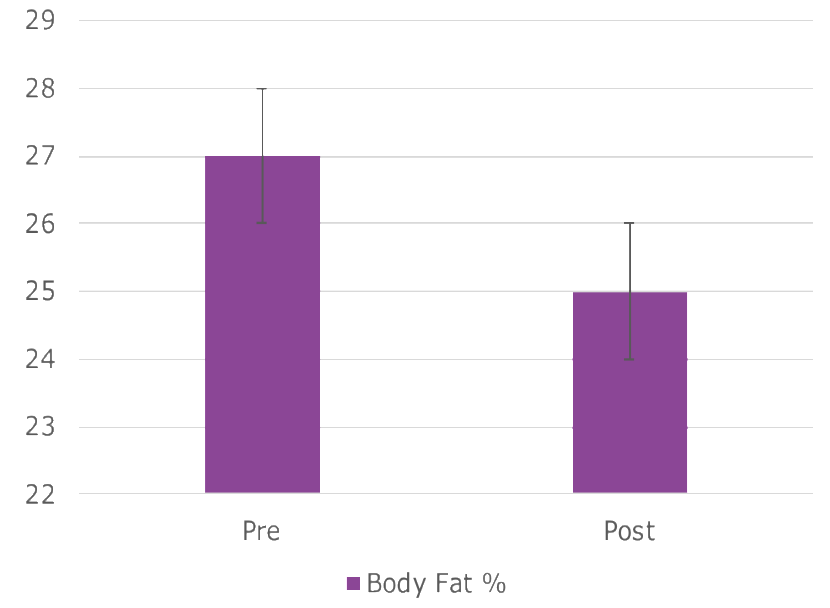

Figure 1. Body Composition

\section{Microbiome Balance}

Following 6 weeks of dietary supplementation, there was a significant increase (relative units) in populations of "good" bacteria (+8\% Bifidobacterium, $+33 \%$ Lactobacillus, $+62 \%$ S. Thermophilus, $+90 \%$ Akkermansia; all $\mathrm{p}<0.05$; Figure $\mathbf{2 A}$ ) as well as bacterial ratios associated with metabolism ( $+6 \%$ composite score, $-11 \%$ Firmicutes, $+6 \%$ Bacteroidetes, $-14 \%$ F/B ratio, all $\mathrm{p}<0.05$; Figure 2B).

\section{Microbiome Composite Score Microbiome Species}
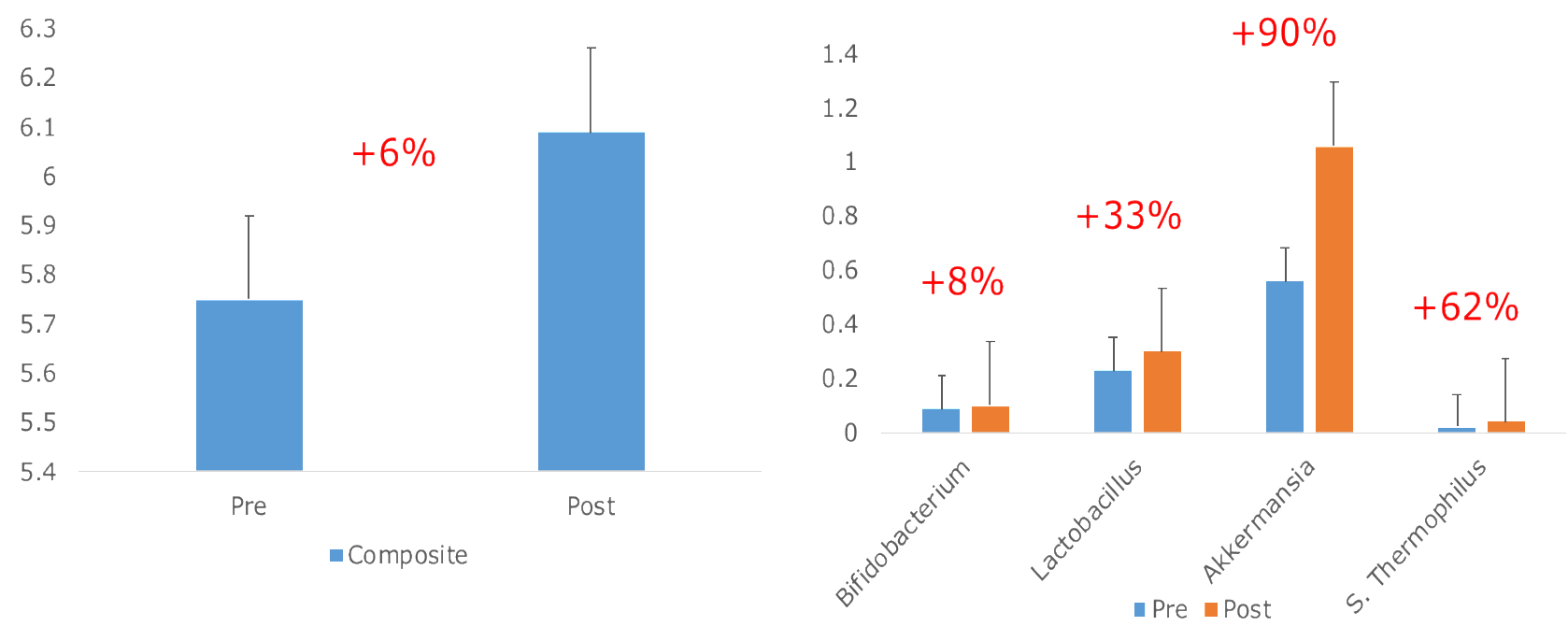

Figure 2A. Microbiome Composition 


\section{Metabolic Ratio}

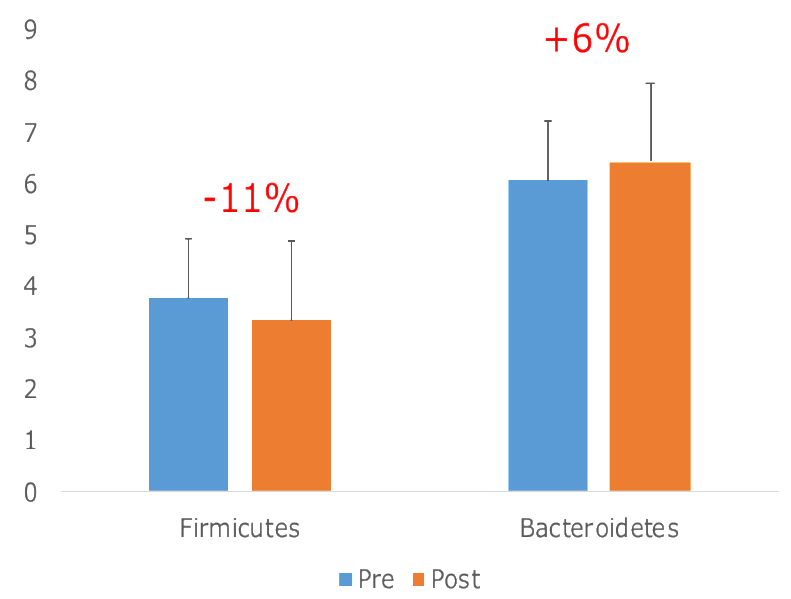

\section{F/B Ratio}

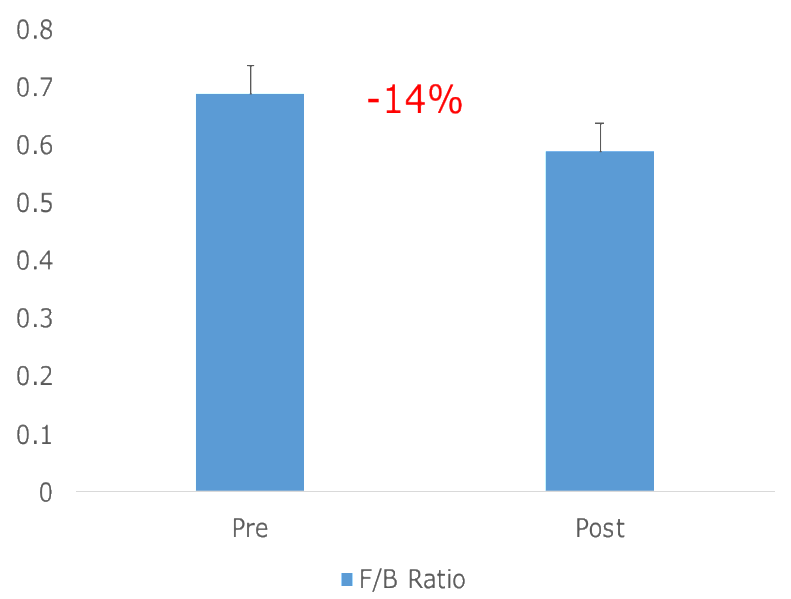

Figure 2B. Microbiome Composition

\section{Metabolic and Cardiovascular Parameters}

Post-supplementation improvements were observed for a variety of metabolites associated with stress, inflammation, and glycemic control (- $11 \%$ cortisol (ng/dl), $+89 \%$ butyrate kinase, $-6 \%$ glucose (mg/dl), all p $<0.05$; Figure 3A), and for blood lipids (-8\% total cholesterol (mg/dl), $-5 \%$ LDL $(\mathrm{mg} / \mathrm{dl}),-23 \%$ triglycerides $(\mathrm{mg} / \mathrm{dl})$, all $\mathrm{p}<0.05$; Figure 3B). The promising $3 \%$ improvement in HDL cholesterol did not reach statistical significance, but that fact that HDL was maintained helped to improve the cardiac risk profile (TC/HDL, $p<0.05$; Figure 3B).

\section{Butyrate Kinase}

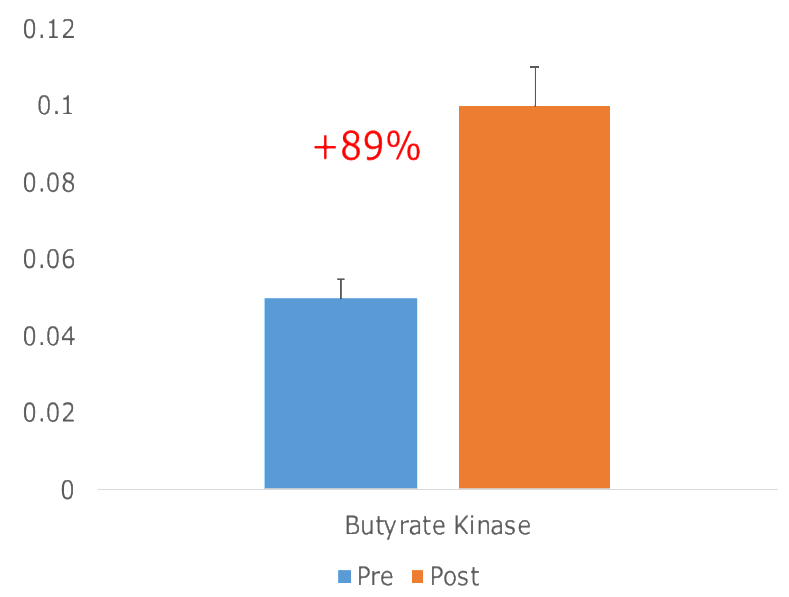

\section{Cortisol}

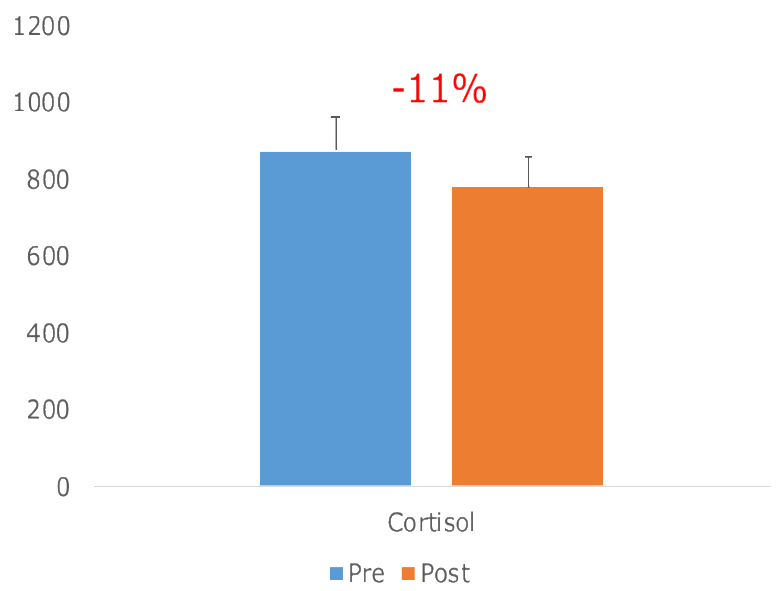

Figure 3A. Metabolic Parameters 

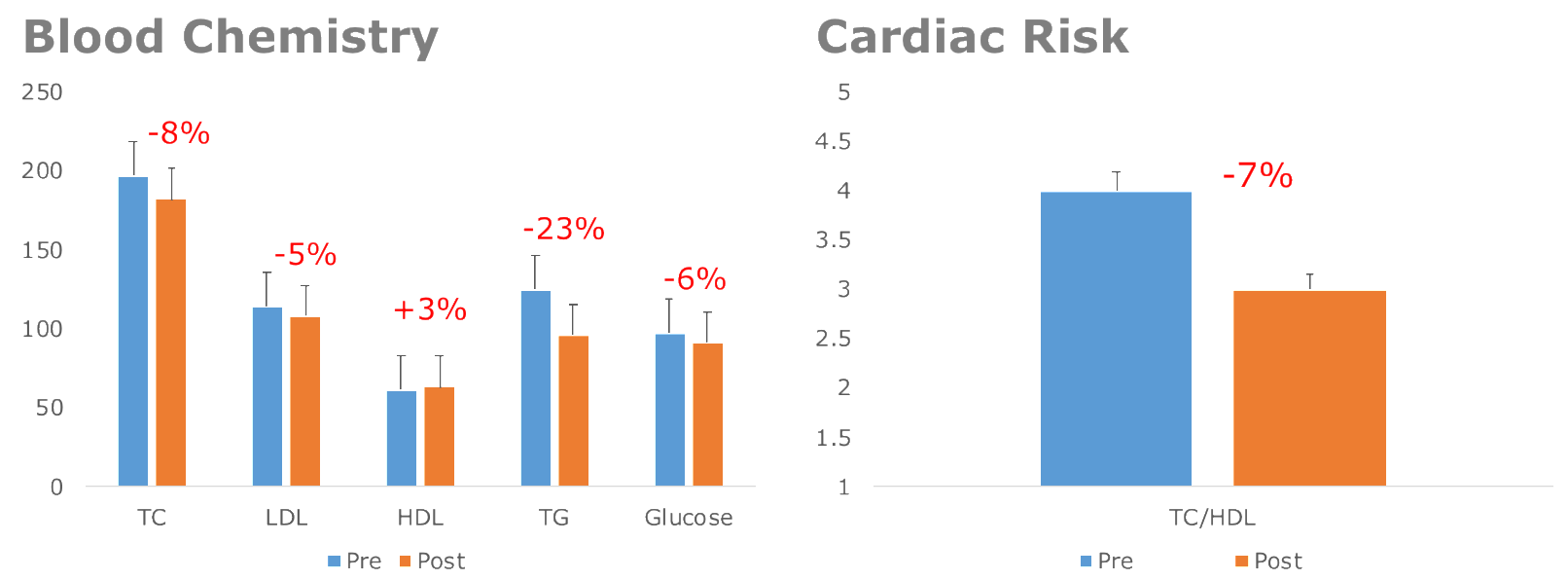

Figure 3B. Cardiovascular Parameters

\section{Psychological Mood State}

Psychological indices were significantly improved (all $\mathrm{p}<0.05$ ) post-supplementation for both positive (+17\% Global Mood; +23\% Vigor) and negative mood states (-38\% Depression; -41\% Tension; -42\% Fatigue; -31\% Confusion; -39\% Anger; Figure 4).

\section{POMS Subscales}

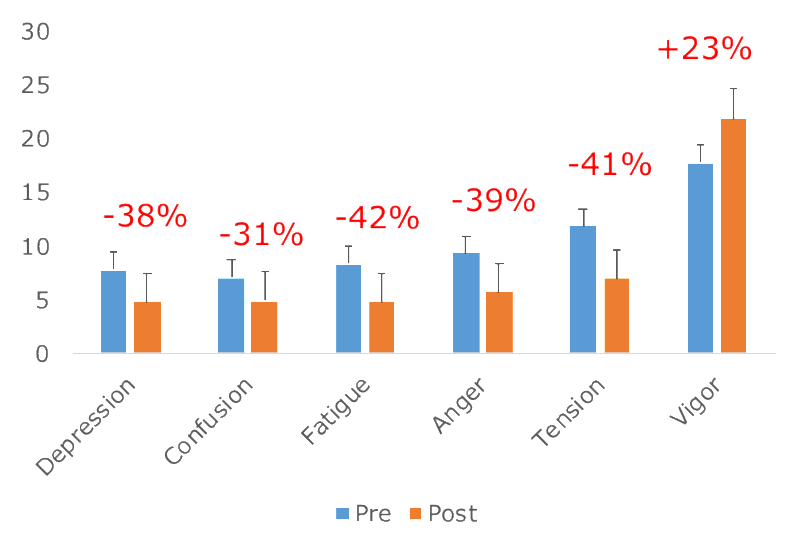

\section{Global Mood State}

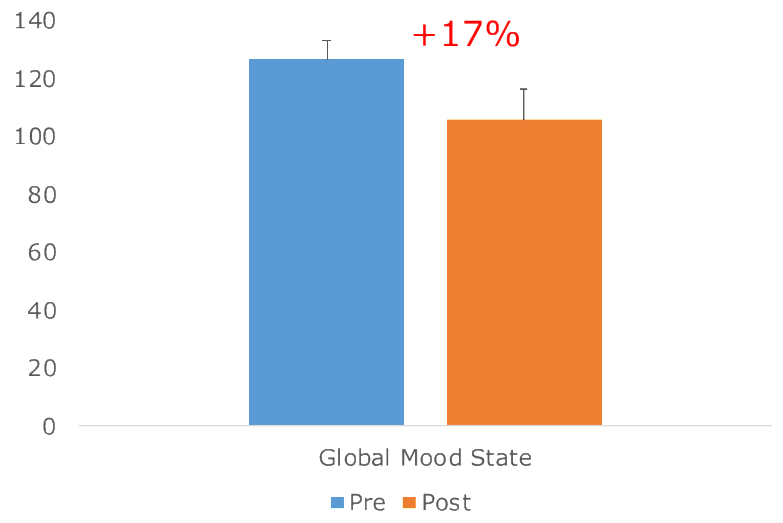

Figure 4. Psychological Mood States

\section{DISCUSSION}

The novelty of the current study is its combination of a number of previously-researched natural ingredients to positively and holistically influence the entire gut-brain axis (gut/microbiome; brain/mood; axis/metabolites) in a population of healthy-stressed subjects. Our subjects represent perhaps the largest subset of the American population who routinely complain of symptoms related to high stress, day-time fatigue, night-time restlessness, low mood, suppressed libido, brain fog, lack of enjoyment (anhedonia/burnout), and general malaise. Such individuals are poor candidates for prescription medications intended for severe disease states such as major depressive disorder 
and generalized anxiety disorders (and their wide range of attendant side effects). As such, there is a pressing need for natural functional food approaches to improve psychological mood state and the emerging understanding of the gut-brain axis in modulating mental wellness represents a promising non-drug approach to help people feel better.

Obesity increases the risk of multiple co-morbidities, including cardiovascular disease, diabetes, hypertension, depression/anxiety, and several cancers, and carries an associated reduction in predicted lifespan. While full obesity reversal is often impractical, even modest, sustained weight loss of $\sim 5 \%$ reduces morbidity and mortality risk.

Potential benefits of gut-brain axis modulation for enhancing weight loss and/or improving mood are often confounded by the multi-factorial nature of each condition, as well as by the disparate nature of different probiotic strains (e.g., single or multi-strain formulation); structure of prebiotic fibers (e.g., preferential usage by certain bacterial species); supplementation dose; and duration of intervention, among others. Nevertheless, a number of recent meta-analyses have reported on dozens of clinical trials across thousands of individuals showing an overall positive benefit of microbiome modulation for weight loss [76-79] and mood improvement [80, 81].

The anti-obesity and anti-depressive activity of gut-brain-axis interventions may be associated with their ability to alter both the structure and function of the microbiome (and associated metabolites including neurotransmitters, hormones, cytokines, short-chain fatty acids, etc.); remodeling of energy metabolism; modulation of gene expression related to appetite and thermogenesis; glucose homeostasis; lipid metabolism; and attenuation of HPA axis activity, among others [76]. The brain sends a variety of signals to the gut via efferent vagal and neuroendocrine pathways, including serotonin, dopamine, and GABA that can modify the intestinal environment, including mucus secretion, immune responses, gut motility, and intestinal barrier function - each of which can influence microbial composition and function [79]. Similarly, the gut sends a variety of signals to the brain via afferent vagal pathways and a wide variety of blood-borne substances (e.g., 70-95\% of the body's serotonin and dopamine are gut-derived) including numerous bioactive molecules involved in appetite and energy balance (e.g., peptide YY, glucagon-like peptide1, cholecystokinin, and ghrelin) [79].

The two largest phyla making up the gut microbiome in humans are Firmicutes and Bacteroidetes, representing $\sim 90 \%$ of all gut microbiota. The relationship between these two large groups, expressed as the Firmicutes/Bacteroidetes (F/B) ratio, has been associated with a number of pathological conditions, including obesity, type 2 diabetes, systemic inflammation, and depression (specifically a greater abundance of Firmicutes and/or a drop in Bacteroidetes, thus an increase in the $\mathrm{F} / \mathrm{B}$ ratio). A number of studies have shown that obese populations tend to have a significantly higher level of Firmicutes and a significantly lower level of Bacteroidetes compared to normal-weight and lean adults [2, 3, 82-84]. Recent interventional trials have shown that the administration of Lactobacillus and Bifidobacterium species can reestablish the F/B ratio and inflammatory tone, thus potentially affecting both mood disorders and obesity through the common gut-brain axis pathways [85, 86].

Highly processed Western-style diets, typically high in fat and sugar and low in fiber and micronutrients, have long been associated with inflammatory diseases, including obesity, diabetes, and depression. Public health recommendations to increase fiber intake, reduce processed food consumption, and increase whole food intake have a positive impact on gut health by stimulating 
the growth and activity of beneficial gut bacteria [87]. In traditional hunter-gatherer societies, high fiber intakes of 50-150 g/day yield a much more diverse gut microbiota with higher colonization by beneficial bacterial species (e.g., Lactobacillus, Bifidobacterium, and Prevotella) and corresponding metabolite richness with higher SCFA production that are associated with lower levels of systemic inflammation [87].

A recent 6-month trial has shown that treatment with a probiotic supplement (10B CFU B. lactis B420), alone or in combination with a prebiotic fiber (12g Litesse Ultra polydextrose), controlled body fat mass, trunk fat mass, and waist circumference, and reduced energy intake in overweight adults $[88,89]$. The B420 strain increases the relative abundance of Akkermansia muciniphila in the gut microbiota, a bacterium linked with improved metabolic health and anti-inflammatory properties. The relative change in body fat mass over six months was $-3.0 \%$ with the probiotic alone, and $-4.5 \%$ with the synbiotic combination of probiotic + prebiotic, which compares favorably with pharmaceutical interventions, in which 3-5\% body weight changes are typically observed for 6-month treatment (e.g., orlistat/Alli/Xenical, liraglutide/Victoza, lorcaserin/Belviq). Reduced energy intake has been observed with supplementation of B420 alone (-300kcal/day) or in combination with polydextrose $(-210 \mathrm{kcal} / \mathrm{day})$, possibly related to the observed increase in microbiome-derived short-chain fatty acids [90]. Unfortunately, the 6-month intervention timeframe, while delivering promising benefits for subjects who successfully complete the fullduration of intervention, is often plagued by poor subject compliance (e.g., $~ 40 \%$ drop out rate), possibly due to the close association between obesity and depression.

One shorter study showed that 4-months of supplementation with Lactobacillus gasseri BNR17 significantly reduced visceral adipose tissue and waist circumference in obese adults [90], while another 4-month supplementation with Lactobacillus rhamnosus CGMCC1.3724, combined with probiotics (inulin and oligofructose), reduced both body weight and hunger scores in obese women [12].

The present study, investigating a very short 1.5-months (6-weeks) of supplementation with targeted probiotic strains, matched prebiotic fibers, and a blend of research-validated phytonutrients targeting gut-brain-axis modulation, showed meaningful improvements in both microbiome structure (bacterial abundance) and function (metabolic activity), as well as positive changes in parameters associated with both physical health (body fat percentage, blood lipids/glucose, and cortisol exposure) and mental health (reduced negative mood states and enhanced positive mood states).

\section{CONCLUSIONS}

The World Health Organization has identified both metabolic issues (e.g., diabetes/obesity) and psychological issues (e.g., depression/anxiety/stress) as urgent public health epidemics threatening global well-being and increasing global health burden. These results demonstrate the close relationship between microbiome balance and both physical and mental health. Importantly, these results also describe the effectiveness of multi-factorial targeted supplementation to positively influence the gut-brain axis for simultaneously improving mental wellness and physical health - owing in large part to the close bi-directional connections across the gut-brain axis and the long-observed associations between obesity and depression. 
List of abbreviations: gamma-Aminobutyric acid (GABA), Polymerase chain reaction (PCR), Profile of Mood States survey (POMS), Short-chain fatty acids (SCFAs), galactooligosaccharide (GOS), isomaltooligosaccharide (IMO).

Competing interests: S.M.T. is an employee of Amare Global, the producer of the Project b3 dietary supplements.

Authors' contributions: S.M.T. designed the research protocol. J.A.T. coordinated the IRB submission, subject recruitment, and study monitoring. B.J.S. and M.J.O. performed and oversaw the microbiome assessments. All authors were involved in the preparation and presentation of these data.

Acknowledgments and Funding: The authors would like to thank the volunteers who contributed their samples, time, and focus to this study and Amare Global for providing the Project b3 dietary supplements and funding the costs associated with microbiome assessments and psychological surveys.

\section{REFERENCES}

1. World Health Organization (WHO) [https://www.who.int/en/news-room/fact-sheets/detail/obesity-and-overweight] Accessed December 1, 2019.

2. World Health Organization (WHO) [https://www.who.int/mental_health/management/depression/en/] Accessed December 1, 2019.

3. Turnbaugh PJ, Ley RE, Mahowald MA, Magrini V, Mardis ER, Gordon JI: An obesityassociated gut microbiome with increased capacity for energy harvest. Nature. 2006;444(7122):1027-1031. DOI:10.1038/nature05414.

4. Ley RE, Turnbaugh PJ, Klein S, Gordon JI: Microbial ecology: human gut microbes associated with obesity. Nature. 2006;444(7122):1022-1023. DOI:10.1038/4441022a.

5. Schachter J, Martel J, Lin CS, et al.: Effects of obesity on depression: A role for inflammation and the gut microbiota. Brain Behav Immun. 2018;69:1-8. DOI:10.1016/j.bbi.2017.08.026.

6. Luppino FS, de Wit LM, Bouvy PF, et al.: Overweight, obesity, and depression: a systematic review and meta-analysis of longitudinal studies. Arch Gen Psychiatry. 2010;67(3):220229. DOI:10.1001/archgenpsychiatry.2010.2.

7. Mulugeta A, Zhou A, Power C, Hypponen E: Obesity and depressive symptoms in mid-life: a population-based cohort study. BMC Psychiatry. 2018;18(1):297. Published 2018 Sep 17. DOI:10.1186/s12888-018-1877-6.

8. Lee SH, Paz-Filho G, Mastronardi C, Licinio J, Wong ML: Is increased antidepressant exposure a contributory factor to the obesity pandemic?. Transl Psychiatry. 2016;6(3):e759. Published 2016 Mar 15. DOI:10.1038/tp.2016.25.

9. Smith KA, Williams C, Cowen PJ: Impaired regulation of brain serotonin function during dieting in women recovered from depression. Br J Psychiatry. 2000;176:72-75. DOI:10.1192/bjp.176.1.72. 
10. Hill C, Guarner F, Reid G, et al.: Expert consensus document. The International Scientific Association for Probiotics and Prebiotics consensus statement on the scope and appropriate use of the term probiotic. Nat Rev Gastroenterol Hepatol. 2014;11(8):506-514. DOI:10.1038/nrgastro.2014.66.

11. Gibson GR, Roberfroid MB: Dietary modulation of the human colonic microbiota: introducing the concept of prebiotics. J Nutr. 1995;125(6):1401-1412. DOI:10.1093/jn/125.6.1401.

12. Dinan TG, Stanton C, Cryan JF: Psychobiotics: a novel class of psychotropic. Biol Psychiatry. 2013;74(10):720-726. DOI:10.1016/j.biopsych.2013.05.001

13. Sanchez M, Darimont C, Drapeau V, et al.: Effect of Lactobacillus rhamnosus CGMCC1.3724 supplementation on weight loss and maintenance in obese men and women. Br J Nutr. 2014;111(8):1507-1519. DOI:10.1017/S0007114513003875.

14. Sanchez M, Darimont C, Panahi S, et al.: Effects of a Diet-Based Weight-Reducing Program with Probiotic Supplementation on Satiety Efficiency, Eating Behaviour Traits, and Psychosocial Behaviours in Obese Individuals. Nutrients. 2017;9(3):284. Published 2017 Mar 15. DOI:10.3390/nu9030284.

15. Kadooka Y, Sato M, Imaizumi K, et al.: Regulation of abdominal adiposity by probiotics (Lactobacillus gasseri SBT2055) in adults with obese tendencies in a randomized controlled trial. Eur J Clin Nutr. 2010;64(6):636-643. DOI:10.1038/ejcn.2010.19.

16. Osterberg KL, Boutagy NE, McMillan RP, et al.: Probiotic supplementation attenuates increases in body mass and fat mass during high-fat diet in healthy young adults. Obesity (Silver Spring). 2015;23(12):2364-2370. DOI:10.1002/oby.21230.

17. Parnell JA, Reimer RA.: Weight loss during oligofructose supplementation is associated with decreased ghrelin and increased peptide YY in overweight and obese adults. Am J Clin Nutr. 2009;89(6):1751-1759. DOI:10.3945/ajcn.2009.27465.

18. Li S, Guerin-Deremaux L, Pochat M, Wils D, Reifer C, Miller LE: NUTRIOSE dietary fiber supplementation improves insulin resistance and determinants of metabolic syndrome in overweight men: a double-blind, randomized, placebo-controlled study. Appl Physiol Nutr Metab. 2010;35(6):773-782. DOI:10.1139/H10-074.

19. Messaoudi M, Violle N, Bisson JF, Desor D, Javelot H, Rougeot C: Beneficial psychological effects of a probiotic formulation (Lactobacillus helveticus R0052 and Bifidobacterium longum R0175) in healthy human volunteers. Gut Microbes. 2011;2(4):256-261. DOI:10.4161/gmic.2.4.16108.

20. Schmidt K, Cowen PJ, Harmer CJ, Tzortzis G, Errington S, Burnet PW: Prebiotic intake reduces the waking cortisol response and alters emotional bias in healthy volunteers. Psychopharmacology (Berl). 2015;232(10):1793-1801. DOI:10.1007/s00213-014-3810-0.

21. Foster LM, Tompkins TA, Dahl WJ: A comprehensive post-market review of studies on a probiotic product containing Lactobacillus helveticus R0052 and Lactobacillus rhamnosus R0011. Benef Microbes. 2011;2(4):319-334. DOI:10.3920/BM2011.0032.

22. Romijn AR, Rucklidge JJ, Kuijer RG, Frampton C: A double-blind, randomized, placebocontrolled trial of Lactobacillus helveticus and Bifidobacterium longum for the symptoms of depression. Aust N Z J Psychiatry. 2017 Aug; 51(8):810-821. Epub 2017 Jan 10. DOI: $10.1177 / 0004867416686694$. 
23. Messaoudi M, Lalonde R, Violle N, Javelot H, Desor D, Nejdi A, Bisson JF, et al.: Assessment of psychotropiclike properties of a probiotic formulation (Lactobacillus helveticus R0052 and Bifidobacterium longum R0175) in rats and human subjects. Br J Nutr. 2011 Mar;105(5):755-64. Epub 2010 Oct 26. DOI: 10.1017/S0007114510004319.

24. Ait-Belgnaoui A, Payard I, Rolland C, Harkat C, Braniste V, Théodorou V, Tompkins TA: Bifidobacterium longum and Lactobacillus helveticus Synergistically Suppress Stress-related Visceral Hypersensitivity Through Hypothalamic-Pituitary-Adrenal Axis Modulation. J Neurogastroenterol Motil. 2018 Jan 30;24(1):138-146. DOI: 10.5056/jnm16167.

25. Messaoudi M, Violle N, Bisson JF, Desor D, Javelot H, Rougeot C: Beneficial psychological effects of a probiotic formulation (Lactobacillus helveticus R0052 and Bifidobacterium longum R0175) in healthy human volunteers. Gut Microbes. 2011 Jul-Aug;2(4):256-61. Epub 2011 Jul 1. DOI: 10.4161/gmic.2.4.16108.

26. Peng HH, Tsai TC, Huang WY, Wu HM, Hsu KS: Probiotic treatment restores normal developmental trajectories of fear memory retention in maternally separated infant rats. Neuropharmacology. 2019 Jul 15;153:53-62. Epub 2019 Apr 26.DOI: 10.1016/j.neuropharm.2019.04.026.

27. Hong M, Kim SW, Han SH, Kim DJ, Suk KT, Kim YS, Kim MJ,et al.: Probiotics (Lactobacillus rhamnosus R0011 and acidophilus R0052) reduce the expression of toll-like receptor 4 in mice with alcoholic liver disease. PLoS One. 2015 Feb 18;10(2):e0117451. DOI: 10.1371/journal.pone.0117451.

28. Grimaldi R, Gibson GR, Vulevic J, Giallourou N, Castro-Mejía JL, Hansen LH, Leigh Gison E, et al.: A prebiotic intervention study in children with autism spectrum disorders (ASDs). Microbiome. 2018 Aug 2;6(1):133. DOI: 10.1186/s40168-018-0523-3.

29. Yang XD, Wang LK, Wu HY, Jiao L: Effects of prebiotic galacto-oligosaccharide on postoperative cognitive dysfunction and neuroinflammation through targeting of the gut-brain axis. BMC Anesthesiol. 2018 Nov 30;18(1):177. DOI:10.1186/s12871-018-0642-1.

30. Schmidt K, Cowen PJ, Harmer CJ, Tzortzis G, Errington S, Burnet PW: Prebiotic intake reduces the waking cortisol response and alters emotional bias in healthy volunteers. Psychopharmacology (Berl). 2015 May; 232(10):1793-801. Epub 2014 Dec 3. DOI:10.1007/s00213-014-3810-0.

31. Mudgil D, Barak S, Patel A, Shah N: Partially hydrolyzed guar gum as a potential prebiotic source. Int J Biol Macromol. 2018;112:207-210. DOI:10.1016/j.ijbiomac.2018.01.164

32. Niv E, Halak A, Tiommny E, Yanai H, Strul H, Naftali T, Vaisman N: Randomized clinical study: Partially hydrolyzed guar gum (PHGG) versus placebo in the treatment of patients with irritable bowel syndrome. Nutr Metab (Lond). 2016 Feb 6;13:10. DOI: 10.1186/s12986-016-0070-5.

33. Yasukawa Z, Inoue R, Ozeki M, Okubo T, Takagi T, Honda A, Naito Y: Effect of Repeated Consumption of Partially Hydrolyzed Guar Gum on Fecal Characteristics and Gut Microbiota: A Randomized, Double-Blind, Placebo-Controlled, and Parallel-Group Clinical Trial. Nutrients. 2019 Sep 10;11(9):2170. DOI:10.3390/nu11092170.

34. Lopes Sakamoto F, Metzker Pereira Ribeiro R, Amador Bueno A, Oliveira Santos H: Psychotropic effects of L-theanine and its clinical properties: From the management of anxiety 
and stress to a potential use in schizophrenia. Pharmacol Res. 2019 Sep;147:104395. Epub 2019 Aug 11. DOI: 10.1016/j.phrs.2019.104395.

35. Hidese S, Ogawa S, Ota M, Ishida I, Yasukawa Z, Ozeki M, Kunugi H: Effects of LTheanine Administration on Stress-Related Symptoms and Cognitive Functions in Healthy Adults: A Randomized Controlled Trial. Nutrients. 2019 Oct 3;11(10):2362. DOI: 10.3390/nu11102362.

36. Unno K, Sumiyoshi A, Konishi T, Hayashi M, Taguchi K, Muguruma Y, Inoue K, et al.: Theanine, the Main Amino Acid in Tea, Prevents Stress-Induced Brain Atrophy by Modifying Early Stress Responses. Nutrients. 2020 Jan 8;12(1):E174. DOI:10.3390/nu12010174.

37. Trost K, Ulaszewska MM, Stanstrup J, Albanese D, De Filippo C, Tuohy KM, Natella F, et al.: Host: Microbiome co-metabolic processing of dietary polyphenols - An acute, single blinded, cross-over study with different doses of apple polyphenols in healthy subjects. Food Res Int. 2018 Oct;112:108-128. Epub 2018 Jun 8. DOI: 10.1016/j.foodres.2018.06.016.

38. Koutsos A, Tuohy KM, Lovegrove JA: Apples and cardiovascular health--is the gut microbiota a core consideration? Nutrients. 2015 May 26;7(6):3959-98. DOI:10.3390/nu7063959.

39. Rana S, Bhushan S: Apple phenolics as nutraceuticals: assessment, analysis and application. J Food Sci Technol. 2016 Apr;53(4):1727-38. Epub 2015 Nov 23. DOI:10.1007/s13197015-2093-8.

40. Park E, Edirisinghe I, Choy YY, Waterhouse A, Burton-Freeman B: Effects of grape seed extract beverage on blood pressure and metabolic indices in individuals with pre-hypertension: a randomised, double-blinded, two-arm, parallel, placebo-controlled trial. Br J Nutr. 2016 Jan 28;115(2):226-38. Epub 2015 Nov 16. DOI:10.1017/S0007114515004328.

41. Terauchi M, Horiguchi N, Kajiyama A, Akiyoshi M, Owa Y, Kato K, Kubota T: Effects of grape seed proanthocyanidin extract on menopausal symptoms, body composition, and cardiovascular parameters in middle-aged women: a randomized, double-blind, placebo-controlled pilot study. Menopause. 2014 Sep; 21(9):990-6. DOI: 10.1097/GME.0000000000000200.

42. Viveros A, Chamorro S, Pizarro M, Arija I, Centeno C, Brenes A: Effects of dietary polyphenol-rich grape products on intestinal microflora and gut morphology in broiler chicks. Poult Sci. 2011 Mar;90(3):566-78. DOI:10.3382/ps.2010-00889.

43. Devaraj S, Vega-Lopez S, Kaul N, Schonlau F, Rohdewald P, Jialal I: Supplementation with a pine bark extract rich in polyphenols increases plasma antioxidant capacity and alters the plasma lipoprotein profile. Lipids. 2002 Oct;37(10):931-4. DOI: 10.1007/s11745-006-09823.

44. Dvorakova M, Sivonova M, Trebaticka J, Skodacek I, Waczulikova I, Muchova J, Durackova $Z$ : The effect of polyphenolic extract from pine bark, Pycnogenol on the level of glutathione in children suffering from attention deficit hyperactivity disorder (ADHD). Redox Rep. 2006;11(4):163-72. DOI:10.1179/135100006X116664.

45. Chovanova Z, Muchova J, Sivonova M, Dvorakova M, Zitnanova I, Waczulíkova I, Trebaticka J,et al.: Effect of polyphenolic extract, Pycnogenol, on the level of 8-oxoguanine in children suffering from attention deficit/hyperactivity disorder. Free Radic Res. 2006 Sep;40(9):1003-10. DOI:10.1080/10715760600824902. 
46. Kujawska M, Jourdes M, Kurpik M, Szulc M, Szaefer H, Chmielarz P, Kreiner G, et al.: Neuroprotective Effects of Pomegranate Juice against Parkinson's Disease and Presence of Ellagitannins-Derived Metabolite-Urolithin A-In the Brain. Int J Mol Sci. 2019 Dec 27;21(1):E202. DOI: 10.3390/ijms21010202.

47. Siddarth P, Li Z, Miller KJ, Ercoli LM, Merril DA, Henning SM, Heber D, et al.: Randomized placebo-controlled study of the memory effects of pomegranate juice in middle-aged and older adults. Am J Clin Nutr. 2020 Jan 1;111(1):170-177. DOI: 10.1093/ajcn/nqz241.

48. Bookheimer SY, Renner BA, Ekstrom A, Li Z, Henning SM, Brown JA, Jones M, et al.: Pomegranate juice augments memory and FMRI activity in middle-aged and older adults with mild memory complaints. Evid Based Complement Alternat Med. 2013; 2013:946298. Epub 2013 Jul 22. DOI: 10.1155/2013/946298.

49. Lazzini S, Polinelli W, Riva A, Morazzoni P, Bombardelli E: The effect of ginger (Zingiber officinalis) and artichoke (Cynara cardunculus) extract supplementation on gastric motility: a pilot randomized study in healthy volunteers. Eur Rev Med Pharmacol Sci. 2016;20(1):146-9.

50. Giacosa A, Guido D, Grassi M, Riva A, Morazzoni P, Bombardelli E, Perna S, et al.: The Effect of Ginger (Zingiber officinalis) and Artichoke (Cynara cardunculus) Extract Supplementation on Functional Dyspepsia: A Randomised, Double-Blind, and Placebo-Controlled Clinical Trial. Evid Based Complement Alternat Med. 2015;2015:915087. DOI: 10.1155/2015/915087. Epub 2015 Apr 14.

51. Valussi M: Functional foods with digestion-enhancing properties. Int J Food Sci Nutr. 2012 Mar;63 Suppl 1:82-9. DOI: 10.3109/09637486.2011.627841. Epub 2011 Oct 19.

52. Fuller R, Moore MV, Lewith G, Stuart BL, Ormiston RV, Fisk HL, Noakes PS, et al.: Yeastderived $\beta-1,3 / 1,6$ glucan, upper respiratory tract infection and innate immunity in older adults. $\quad$ Nutrition. 2017 Jul-Aug;39-40:30-35. Epub 2017 Mar 23. DOI:10.1016/j.nut.2017.03.003.

53. Talbott SM, Talbott JA: Baker's yeast beta-glucan supplement reduces upper respiratory symptoms and improves mood state in stressed women. J Am Coll Nutr. 2012 Aug;31(4):295-300. DOI: 10.1080/07315724.2012.10720441.

54. Talbott S, Talbott J: Effect of BETA 1, 3/1, 6 GLUCAN on Upper Respiratory Tract Infection Symptoms and Mood State in Marathon Athletes. J Sports Sci Med. 2009 Dec $1 ; 8(4): 509-15$.

55. Dai X, Stanilka JM, Rowe CA, Esteves EA, Nieves C Jr, Spaiser SJ, Christman MC, et al.: Consuming Lentinula edodes (Shiitake) Mushrooms Daily Improves Human Immunity: A Randomized Dietary Intervention in Healthy Young Adults. J Am Coll Nutr. 2015;34(6):478-87. Epub 2015 Apr 11. DOI:10.1080/07315724.2014.950391.

56. Gaullier JM, Sleboda J, Ofjord ES, Ulvestad E, Nurminiemi M, Moe C, Tor A, et al.: Supplementation with a soluble $\beta$-glucan exported from Shiitake medicinal mushroom, Lentinus edodes (Berk.) singer mycelium: a crossover, placebo-controlled study in healthy elderly. Int J Med Mushrooms. 2011;13(4):319-26. DOI: 10.1615/intjmedmushr.v13.i4.10. 
57.Zembron-Lacny A, Gajewski M, Naczk M, Siatkowski I: Effect of shiitake (Lentinus edodes) extract on antioxidant and inflammatory response to prolonged eccentric exercise. J Physiol Pharmacol. 2013 Apr;64(2):249-54.

58. Wright CM, Bezabhe W, Fitton JH, Stringer DN, Bereznicki LRE, Peterson GM: Effect of a Fucoidan Extract on Insulin Resistance and Cardiometabolic Markers in Obese, Nondiabetic Subjects: A Randomized, Controlled Trial. J Altern Complement Med. 2019 Mar;25(3):346-352. Epub 2018 Oct 12. PMID: 30312135. DOI: 10.1089/acm.2018.0189.

59. Reid SNS, Ryu JK, Kim Y, Jeon BH: The Effects of Fermented Laminaria japonica on ShortTerm Working Memory and Physical Fitness in the Elderly. Evid Based Complement Alternat Med. 2018 Jun 12;2018:8109621. DOI:10.1155/2018/8109621.

60. Walsh AM, Sweeney T, O'Shea CJ, Doyle DN, O'Doherty JV: Effects of supplementing dietary laminarin and fucoidan on intestinal morphology and the immune gene expression in the weaned pig. J Anim Sci. 2012 Dec;90 Suppl 4:284-6. DOI: 10.2527/jas.53949.

61. Roshanravan N, Mahdavi R, Alizadeh E, Jafarabadi MA, Hedayati M, Ghavami A, Alipour S, et al.: Effect of Butyrate and Inulin Supplementation on Glycemic Status, Lipid Profile and Glucagon-Like Peptide 1 Level in Patients with Type 2 Diabetes: A Randomized Double-Blind, Placebo-Controlled Trial. Horm Metab Res. 2017 Nov;49(11):886-891. Epub 2017 Sep 29. DOI:10.1055/s-0043-119089.

62. Boets E, Gomand SV, Deroover L, Preston T, Vermeulen K, De Preter V, Hamer HM, Van den Mooter G, et al.: Systemic availability and metabolism of colonic-derived short-chain fatty acids in healthy subjects: a stable isotope study. J Physiol. 2017 Jan 15;595(2):541555. Epub 2016 Sep 18. DOI: 10.1113/JP272613.

63. 62.Van der Beek CM, Canfora EE, Kip AM, Gorissen SHM, Olde Damink SWM, van Eijk HM, Holst JJ, et al.: The prebiotic inulin improves substrate metabolism and promotes shortchain fatty acid production in overweight to obese men. Metabolism. 2018 Oct;87:25-35. DOI:10.1016/j.metabol.2018.06.009. Epub 2018 Jun 25.

64. Davison G, Marchbank T, March DS, Thatcher R, Playford RJ: Zinc carnosine works with bovine colostrum in truncating heavy exercise-induced increase in gut permeability in healthy volunteers. Am J Clin Nutr. 2016 Aug;104(2):526-36. Epub 2016 Jun 29. DOI:10.3945/ajen.116.134403.

65. Itagaki M, Saruta M, Saijo H, Mitobe J, Arihiro S, Matsuoka M, Kato T, et al.: Efficacy of zinc-carnosine chelate compound, Polaprezinc, enemas in patients with ulcerative colitis. Scand J Gastroenterol. 2014 Feb;49(2):164-72. Epub 2013 Nov 29. DOI: 10.3109/00365521.2013.863963.

66. Mahmood A, FitzGerald AJ, Marchbank T, Ntatsaki E, Murray D, Ghosh S, Playford RJ. Zinc carnosine, a health food supplement that stabilises small bowel integrity and stimulates gut repair processes. Gut. 2007 Feb;56(2):168-75. Epub 2006 Jun 15. DOI: 10.1136/gut.2006.099929.

67. Dai Z, Lyu W, Xie M, Yuan Q, Ye H, Hu B, Zhou L, et al.: Effects of $\alpha$-Galactooligosaccharides from Chickpeas on High-Fat-Diet-Induced Metabolic Syndrome in Mice. J Agric Food Chem. 2017 Apr 19;65(15):3160-3166. Epub 2017 Apr 6. DOI:10.1021/acs.jafc.7b00489. 
68. Pittaway JK, Ahuja KD, Cehun M, Chronopoulos A, Robertson IK, Nestel PJ, Ball MJ: Dietary supplementation with chickpeas for at least 5 weeks results in small but significant reductions in serum total and low-density lipoprotein cholesterols in adult women and men. Ann Nutr Metab. 2006;50(6):512-8. Epub 2006 Dec 21. DOI:10.1159/000098143.

69. Pittaway JK, Robertson IK, Ball MJ: Chickpeas may influence fatty acid and fiber intake in an ad libitum diet, leading to small improvements in serum lipid profile and glycemic control. J Am Diet Assoc. 2008 Jun;108(6):1009-13. DOI:10.1016/j.jada.2008.03.009.

70. Takanari J, Nakahigashi J, Sato A, Waki H, Miyazaki S, Uebaba K, Hisajima T: Effect of Enzyme-Treated Asparagus Extract (ETAS) on Psychological Stress in Healthy Individuals. J Nutr Sci Vitaminol (Tokyo). 2016;62(3):198-205. DOI:10.3177/jnsv.62.198.

71. Ito T, Maeda T, Goto K, Miura T, Wakame K, Nishioka H, Sato A: Enzyme-treated asparagus extract promotes expression of heat shock protein and exerts antistress effects. J Food Sci. 2014 Mar;79(3):H413-9. Epub 2014 Feb 5. DOI:10.1111/1750-3841.12371.

72. Ito T, Goto K, Takanari J, Miura T, Wakame K, Nishioka H, Tanaka A, Nishihira J: Effects of enzyme-treated asparagus extract on heat shock protein 70, stress indices, and sleep in healthy adult men. J Nutr Sci Vitaminol (Tokyo). 2014;60(4):283-90. DOI: 10.3177/jnsv.60.283.

73. Terakawa N, Matsui Y, Satoi S, Yanagimoto H, Takahashi K, Yamamoto T, Yamao J, et al.: Immunological effect of active hexose correlated compound (AHCC) in healthy volunteers: a double-blind, placebo-controlled trial. Nutr Cancer. 2008;60(5):643-51. DOI:10.1080/01635580801993280.

74. Spierings EL, Fujii H, Sun B, Walshe T: A Phase I study of the safety of the nutritional supplement, active hexose correlated compound, AHCC, in healthy volunteers. J Nutr Sci Vitaminol (Tokyo). 2007 Dec;53(6):536-9. DOI:10.3177/jnsv.53.536.

75. Roman BE, Beli E, Duriancik DM, Gardner EM: Short-term supplementation with active hexose correlated compound improves the antibody response to influenza B vaccine. Nutr Res. 2013 Jan;33(1):12-7. Epub 2012 Dec 4. DOI: 10.1016/j.nutres.2012.11.001.

76. Rossi V, Pourtois G: Transient state-dependent fluctuations in anxiety measured using STAI, POMS, PANAS or VAS: a comparative review. Anxiety Stress Coping. 2012;25(6):603645. DOI:10.1080/10615806.2011.582948.

77. Sivamaruthi BS, Kesika P, Suganthy N, Chaiyasut C: A Review on Role of Microbiome in Obesity and Antiobesity Properties of Probiotic Supplements. Biomed Res Int. 2019;2019:3291367. Published 2019 May 9. DOI:10.1155/2019/3291367.

78. Castaner O, Goday A, Park YM, et al: The Gut Microbiome Profile in Obesity: A Systematic Review. Int J Endocrinol. 2018;2018:4095789. Published 2018 Mar 22. DOI:10.1155/2018/4095789.

79. Muscogiuri G, Cantone E, Cassarano S, et al: Gut microbiota: a new path to treat obesity. Int J Obes Suppl. 2019;9(1):10-19. DOI:10.1038/s41367-019-0011-7.

80. Lazar V, Ditu LM, Pircalabioru GG, et al.: Gut Microbiota, Host Organism, and Diet Trialogue in Diabetes and Obesity. Front Nutr. 2019;6:21. Published 2019 Mar 13. DOI:10.3389/fnut.2019.00021. 
81. Ng QX, Peters C, Ho CYX, Lim DY, Yeo WS: A meta-analysis of the use of probiotics to alleviate depressive symptoms. J Affect Disord. 2018;228:13-19. DOI:10.1016/j.jad.2017.11.063.

82. McKean J, Naug H, Nikbakht E, Amiet B, Colson N: Probiotics and Subclinical Psychological Symptoms in Healthy Participants: A Systematic Review and Meta-Analysis. J Altern Complement Med. 2017;23(4):249-258. DOI:10.1089/acm.2016.0023.

83. Koliada A, Syzenko G, Moseiko V, et al.: Association between body mass index and Firmicutes/Bacteroidetes ratio in an adult Ukrainian population. BMC Microbiol. 2017;17(1):120. Published 2017 May 22. DOI:10.1186/s12866-017-1027-1.

84. Mariat D, Firmesse O, Levenez F, et al.: The Firmicutes/Bacteroidetes ratio of the human microbiota changes with age. BMC Microbiol. 2009;9:123. Published 2009 Jun 9. DOI:10.1186/1471-2180-9-123.

85. Indiani CMDSP, Rizzardi KF, Castelo PM, Ferraz LFC, Darrieux M, Parisotto TM: Childhood Obesity and Firmicutes/Bacteroidetes Ratio in the Gut Microbiota: A Systematic Review. Child Obes. 2018;14(8):501-509. DOI:10.1089/chi.2018.0040.

86. Ohland CL, Kish L, Bell H, et al.: Effects of Lactobacillus helveticus on murine behavior are dependent on diet and genotype and correlate with alterations in the gut microbiome. Psychoneuroendocrinology. 2013;38(9):1738-1747. DOI:10.1016/j.psyneuen.2013.02.008.

87. Abildgaard A, Elfving B, Hokland M, Wegener G, Lund S: Probiotic treatment reduces depressive-like behaviour in rats independently of diet. Psychoneuroendocrinology. 2017;79:40-48. DOI:10.1016/j.psyneuen.2017.02.014.

88. Cotillard A, Kennedy SP, Kong LC, et al: Dietary intervention impact on gut microbial gene richness [published correction appears in Nature. 2013 Oct 24;502(7472)580]. Nature. 2013;500(7464):585-588. DOI:10.1038/nature12480.

89. Stenman LK, Lehtinen MJ, Meland N, Christensen JE, Yeung N, Saarinen MT, Courtney M, et al.: Probiotic With or Without Fiber Controls Body Fat Mass, Associated With Serum Zonulin, in Overweight and Obese Adults-Randomized Controlled Trial. EBioMedicine. 2016 Nov;13:190-200. DOI: 10.1016/j.ebiom.2016.10.036. Epub 2016 Oct 26.

90. Hibberd AA, Yde CC, Ziegler ML, Honoré AH, Saarinen MT, Lahtinen S, Stahl B, et al.: Probiotic or synbiotic alters the gut microbiota and metabolism in a randomised controlled trial of weight management in overweight adults. Benef Microbes. 2019 Mar 13;10(2):121135. Epub 2018 Dec 10. DOI: 10.3920/BM2018.0028.

91. Kim J, Yun JM, Kim MK, Kwon O, Cho B: Lactobacillus gasseri BNR17 Supplementation Reduces the Visceral Fat Accumulation and Waist Circumference in Obese Adults: A Randomized, Double-Blind, Placebo-Controlled Trial. J Med Food. 2018;21(5):454-461. DOI:10.1089/jmf.2017.3937. 